\title{
NO FAREWELL TO INTERPRETATION
}

\author{
Cornelius Holtorf
}

As Bjørnar Olsen knows very well, the task he has been given is in equal measure difficult and thankless. His discussion paper is inevitably personal, characterized both by "intellectual narcissism" in assessing the present and by a fair degree of wishful thinking in predicting the future. He hopes that what he has to say "may be interesting to discuss". Alas, I find quite a bit in this paper valid but unspectacular and not particularly interesting to discuss at all. However, there are also a few things in the paper which I find interesting to disagree with.

I for one am an archaeologist who does not hold things "dearest" or considers them the "core subject matter" of archaeology. Neither do I agree that "a concern with things themselves, exploring their intrinsic qualities, is indispensable to any archaeology." In fact, I have never been very interested in things at all. Rather than archaeology being "the discipline of things par excellence", I insist that archaeology is mainly the study of the past and its remains in the present. The difference may not sound enormous but to me interpretations of the past are a crucial spice in the archaeological soup without which even the most ecologically produced, thingly ingredients remain tasteless. I therefore have some reservations when Olsen energetically advocates here, as elsewhere, a (re)turn to things as the next big hope for archaeology as a discipline (Olsen 20IO).

It strikes me that another Norwegian archaeologist, Brit Solli (20II), has recently argued along similar lines, although more related to heritage issues. Her rejection of constructivism, which is partly motivated by a nostalgic desire for universal values and principles, leads her to sub- 
scribe to a "mitigated essentialism" (20I I:47). She insists upon the existence of essential values and qualities of material things and environmental processes that somehow become independent agents in human history, overdetermining the work of archaeologists. As I argued in an earlier discussion with her (Holtorf 20II), I cannot see how any such assertions can advance our discipline, which surely needs to use living human beings rather than essentialized objects or climate curves as its main point of reference. It is the human factor that continues to bring about and shape things and processes, making them meaningful and significant in each present (Holtorf 2002).

Whereas the definition of the core of archaeology may be a matter of friendly debate and emphasis, more serious are Olsen's programmatic statements concerning the way in which archaeologists are supposed to work. Despite the intellectual vibrancy of his own past contributions to the theory of archaeological interpretation (e.g. Olsen 1990), he is not now very fond of what he calls "our current obsession with turning mute things into storytellers or otherwise loading them with interpretative burdens they mostly are unfit to carry." He therefore seeks an alternative to what he considers are the "current regimes of interpretation and intellectualization". In this spirit, Olsen claims, things need to be recognized "as things" and they may be "the source of their own signification": a boat, he suggests, is significant for being a boat and nothing else. Such a truism surely invites an analysis and indeed interpretation of what Olsen actually means, for every sentence is not only a sentence but also a transmitter of meaning. Contrary, I suspect, to his intentions, Olsen's tautological reasoning is a form of anti-theory that seemingly makes do without the high-flying interpretive approaches he so much wants to leave behind him. But by asserting for his claims the status of an alternative to conventional interpretations, Olsen pursues a risky intellectual strategy. His ambition to remove his own interpretive approach from the general archaeological playing field of competing theories and "intellectualizations" is anything but hidden and indeed easy to see through. It makes little sense that the ideas of Bjørnar Olsen, of all archaeologists, should be somehow separate from other archaeologists' ideas. The chances are therefore that in due course we will not be witnessing a general "farewell to interpretation" but possibly more likely a farewell to Olsen's farewell to interpretation - soon to be superseded by other intellectualizations, thus becoming a thing of the past, and then perhaps worth being studied as such.

In the end I expect that Olsen (and for that matter Solli) will agree with me that although it may be true that over the past couple of decades the previously dominant style of archaeological theorizing has changed 
and a more pragmatic and eclectic way of archaeological reasoning has been spreading, this does not mean that archaeological theory and intellectual reasoning as such are dead (cf. Bintliff \& Pearce 20II). I consider Olsen's own paper to be a good manifestation of this realization, not because he offers something profoundly new and different but precisely because he offers a variation on some of the themes of archaeological interpretation and intellectualism that have been with us for decades.

Archaeological theory is about ideas and about thoughtful practice. To the extent that Olsen's suggestions contribute to archaeological theory defined in this way, they are more than welcome. For example, his recent co-authored work on a recently deserted mining town in Svalbard is highly original and stimulates archaeological practice in many interesting ways (Andreassen, Bjerck \& Olsen 20Io). It has to be said, however, that the most compelling sections of the book are not those about the deserted town and all its splendid things but Hein Bjerck's personal account of he group's fieldwork, joined up with his reminiscences from when the town was still inhabited by people. I therefore have my doubts that some of Bjørnar Olsen's rather more radical claims about "a new and more interesting archaeology" turning to "things themselves" - things that are intended to be liberated from human story-telling and interpretation and instead to be recognized "as things" - will ever come to sound "mild and normal".

Cornelius Holtorf
Archaeology, School of Cultural Sciences
Linnaeus University
391 82 Kalmar
Sweden

\section{REFERENCES}

Andreassen, E., Bjerck, H. B. \& Olsen, B. 20Io. Persistent Memories. Pyramiden - a Soviet Mining Town in the High Arctic. Trondheim: Tapir Academic Press.

Bintliff, J. \& Pearce, M. (Eds). 20Ir. The Death of Archaeological Theory? Oxford: Oxbow.

Holtorf, C. 2002. Notes on the Life History of a Pot Sherd. Journal of Material Culture 7, 49-7I.

Holtorf, C. 20I r. On the Future Significance of Heritage (comment on Solli). Norwegian Archaeological Review 44(I), 64-66.

Olsen, B. I990. Roland Barthes: From Sign to Text. In: Christopher Tilley (Ed.). Reading Material Culture. Pp. I63-206. Oxford: Blackwell. 
Olsen, B. 20Io. In Defense of Things. Archaeology and the Ontology of Objects. Lanham: Altamira Press.

Solli, B. 20II. Some Reflections on Heritage and Archaeology in the Anthropocene (with nine comments and a reply). Norwegian Archaeological Review 44(I), 40-88. 